\title{
Vinylcyclopropanes as All-Carbon 1,5-Dipoles: A Reactivity Switch for Palladium-Catalyzed (5+4) Cycloadditions
}

\author{
Anaïs Scuiller ${ }^{\dagger}$ Alexandre Karnat,${ }^{\dagger}$ Nicolas Casaretto, ${ }^{\ddagger}$ and Alexis Archambeau ${ }^{*}, \dagger$ \\ ${ }^{\dagger}$ Laboratoire de Synthèse Organique, UMR 7652, Ecole Polytechnique, ENSTA ParisTech, CNRS, 91128 Palaiseau Cedex, \\ France. \\ ${ }^{\ddagger}$ Laboratoire de Chimie Moléculaire, UMR 9168, Ecole Polytechnique, CNRS, 91128 Palaiseau Cedex, France. \\ Supporting Information Placeholder
}

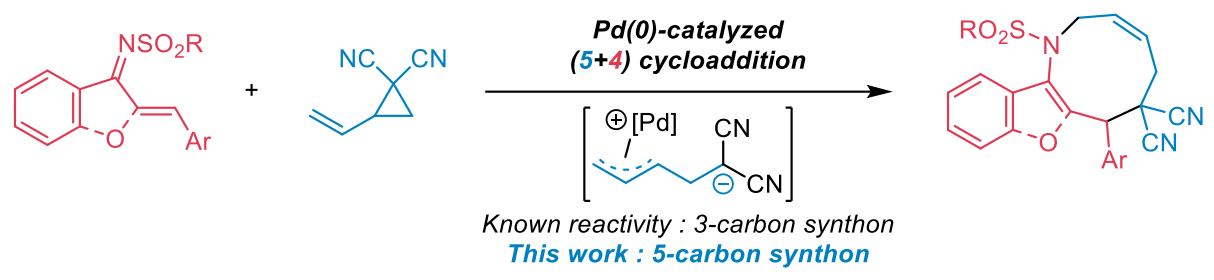

ABSTRACT: Azonanes were prepared by a palladium-catalyzed (5+4) cycloaddition between activated vinylcyclopropanes and 1-azadienes. During this process, the vinylcyclopropane partner displayed an unusual reactivity and behave as an all-carbon 1,5dipole. A $N, N$-bidentate ligand was required to inhibit the formation of thermodynamic $(3+2)$ cycloadducts.

When a multitude of methods describes the preparation of 3 to 7 membered-rings, the synthesis of mediumsized ( 8 to 11 ) heterocycles ${ }^{1,2}$ remains a more demanding task because of the high entropy and enthalpy associated with the cyclization process. ${ }^{3}$ Our group is interested in the design of new cycloaddition strategies for the preparation of these important structures and we focused our attention on the design and reactivity of $1, n$-dipoles $(n \geq 4)$ whose application for medium-rings synthesis is still limited. ${ }^{4}$

Transition-metal catalyzed cycloadditions relying on Tsuji-Trost chemistry has recently emerged as a valuable approach towards $\pi$-allyl-Pd" $1, n$-zwitterionic dipoles. ${ }^{5-7}$ Following the pioneering work of Zhao, vinylethylene carbonates (and, to a lesser extent, the corresponding oxiranes) have recently gathered a growing attention as readily available oxa-1,5-dipole precursors (Scheme 1a). ${ }^{8,9}$ The relevance of nitrogenated heterocycles prompted organic chemists to study new aza-dipoles. ${ }^{10}$ Tunge and others demonstrated the versatility of vinyl benzoxazinones in a wide array of Pd-catalyzed $(4+n)$ cycloadditions (Scheme $1 \mathrm{~b}$ ). ${ }^{11}$ The negative charge of the zwitterionic $\pi$-allyl-Pd" intermediates could also be stabilized as a soft enolate by electron withdrawing neighboring groups and cycloadditions of all-carbon 1,4-dipoles were pioneered by Hayashi and Shintani using $\gamma$-methylidene- $\delta$-valerolactones as readily available substrates. ${ }^{12}$ Recently, the group of Trost designed two acyclic substrates, precursors of trimethylenemethane homologues, allowing for the enantioselective formation of diversely substituted cyclohexanes ${ }^{13}$ and cyclohexanones ${ }^{14}$ (Scheme 1c). To the best of our knowledge,

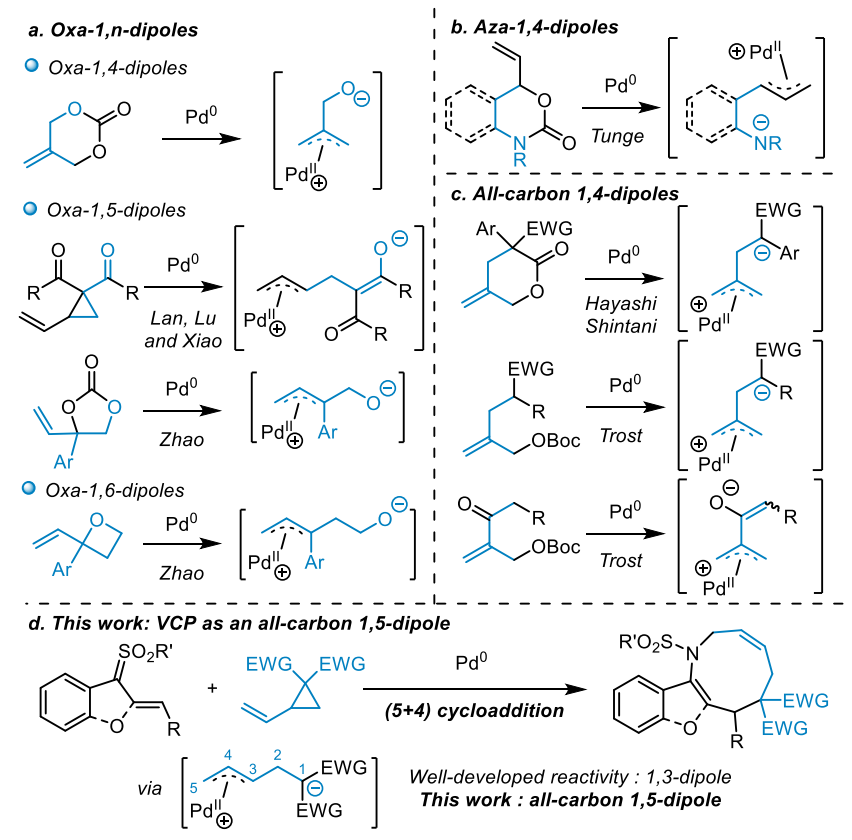

Scheme 1. 1,n-dipoles ( $n \geq 4)$ in Tsuji-Trost chemistry. 
cycloadditions of all-carbon 1,5-dipoles relying on Tsuji-Trost chemistry have not been disclosed yet. ${ }^{15}$ Acknowledging that such zwitterionic intermediates could contribute to the preparation of new medium-sized cyclic structures, we envisioned to involve VCPs as their precursors.

While these substrates have been well established as 3-carbon synthons in $\mathrm{Pd}(0)$ catalysis, ${ }^{16}$ we anticipated that steric hindrance at the nucleophilic site of a cycloaddition partner would promote a faster cyclization step at the $\mathrm{C}_{5}$ carbon. Herein we report a kinetically-controlled Pd-catalyzed $(5+4)$ cycloaddition of activated vinylcyclopropanes with 1-azadienes ${ }^{8 \mathrm{a}, 8 \mathrm{~b}, 9 \mathrm{a}}$ for the synthesis of azonane heterocycles (Scheme 1d).
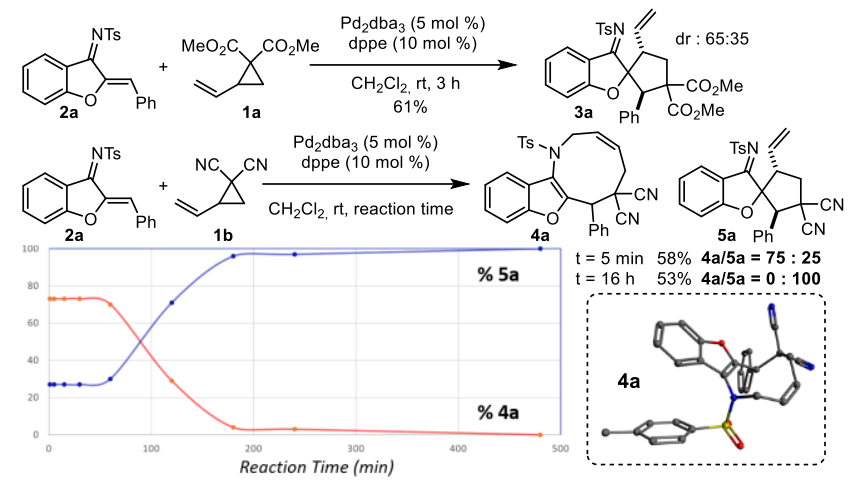

Scheme 2. Preliminary studies

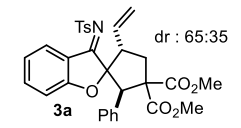

To conduct this study, we initially involved VCP 1a bearing two methyl ester groups and benzofuran-derived 1azadiene $\mathbf{2 a}$ as test substrates. Under usual conditions $\left(\mathrm{Pd}_{2} \mathrm{dba}_{3}\right.$, dppe, $\mathrm{CH}_{2} \mathrm{Cl}_{2}$, rt $)$, we observed the formation of spiro compound 3 a originating from a $(3+2)$ cycloaddition involving the VCP as a nucleophilic 1,3-dipole and the $\mathrm{C}=\mathrm{C}$ bond of the azadiene as an electrophilic 1,2-dipole. ${ }^{17} \mathrm{~A}$ remarkably different outcome was observed with VCP 1b bearing two cyano electron-withdrawing groups. Under the same conditions, a fast transformation ( $<1 \mathrm{~min}$ ) was observed and furnished the expected 9-membered ring $4 \mathbf{a}^{18}$ as a major product along with a mixture of diastere-

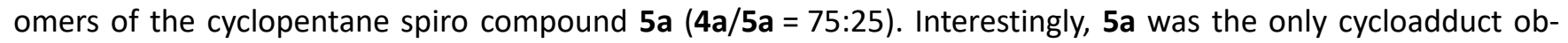
served after 4 hours ( $\mathrm{rt}$ ) and a careful monitoring of the $4 \mathrm{a} / 5 \mathrm{a}$ ratio by ${ }^{1} \mathrm{H}$ NMR spectroscopy revealed that $(5+4)$ cycloadduct 4a was gradually converted to $(3+2)$ cycloadduct 5a under these reaction conditions (Scheme 2).

After this encouraging preliminary result, an array of solvents was tested but did not allow for a more selective formation of 9-membered azonane 4a (Table 1, Entry 1-5). Gratifyingly, a $\mathrm{Pd}_{2} \mathrm{dba}_{3} / \mathrm{N}, \mathrm{N}$-bidentate ligand catalytic system led to the exclusive formation of the $(5+4)$ cycloadduct $4 a(4 a / 5 a>96: 4)$ which was isolated in good yield (74\%) using phenanthroline as ligand (Table 1, Entry 7) and, in this case, no conversion of $\mathbf{4 a}$ to $\mathbf{5 a}$ was observed after 16 hours (Table 1, Entry 8). These conditions proved to be suitable for the gram-scale synthesis $(1.10 \mathrm{~g}, 73 \%)$ of 2 a (Table 1, Entry 9). It is worth pointing out that VCP 1a bearing two methyl esters was exclusively converted to the corresponding spiro compound under these conditions, highlighting the importance of the two cyano groups. ${ }^{19}$

Table 1. Optimization of the reaction conditions ${ }^{a}$

\begin{tabular}{|c|c|c|c|c|}
\hline Entry & Ligand & Solvent & $4 a / 5 a$ & Yield (\%) \\
\hline 1 & dppe & $\mathrm{CH}_{2} \mathrm{Cl}_{2}$ & $75: 25$ & $58^{b}$ \\
\hline 2 & dppe & Toluene & $72: 28$ & $42^{b}$ \\
\hline 3 & dppe & Methanol & $65: 35$ & $41^{b}$ \\
\hline 4 & dppe & $\mathrm{Et}_{2} \mathrm{O}$ & $65: 35$ & $62^{b}$ \\
\hline 5 & dppe & Acetone & $63: 37$ & $56^{b}$ \\
\hline 6 & bipyridine & $\mathrm{CH}_{2} \mathrm{Cl}_{2}$ & $>96: 4$ & $64^{c}$ \\
\hline $7^{d}$ & phenanthroline & $\mathrm{CH}_{2} \mathrm{Cl}_{2}$ & $>96: 4$ & $74^{c}$ \\
\hline $8^{e}$ & phenanthroline & $\mathrm{CH}_{2} \mathrm{Cl}_{2}$ & $>96: 4$ & $71^{c}$ \\
\hline $9^{f}$ & phenanthroline & $\mathrm{CH}_{2} \mathrm{Cl}_{2}$ & $>96: 4$ & $73^{c}$ \\
\hline
\end{tabular}

${ }^{a}$ Reaction conditions: $\mathbf{1 b}(0.075 \mathrm{mmol}), \mathbf{2 a}(0.05 \mathrm{mmol}), \mathrm{Pd}_{2} \mathrm{dba}_{3}(0.0025 \mathrm{mmol})$, ligand $(0.005 \mathrm{mmol})$ in solvent $(0.5 \mathrm{~mL})$ at room temperature. ${ }^{b} \mathrm{NMR}$ yields ${ }^{c}$ Isolated yields. ${ }^{d}$ Reaction time: $5 \mathrm{~min}$. ${ }^{e}$ Reaction time: $16 \mathrm{~h} .{ }^{f} \mathbf{2 a}$ (3.00 $\mathrm{mmol})$, Reaction time: $5 \mathrm{~min}$. 
Having these optimized conditions in hand, we then examined the scope of this $(5+4)$ cycloaddition by involving benzofuran-derived azadienes bearing an array of aromatic substituents at position $\mathrm{C}_{4}$. Electron-rich phenyl groups were well tolerated and azonane with $p$-anisyl (4b), $p$-tolyl (4c), 3,4-dimethoxyphenyl (4d) and $m$-methoxyphenyl (4e) groups were smoothly generated. Steric hindrance on this aromatic group had little influence on this cycloaddition as azadienes $\mathbf{2 f}(\mathbf{8 2} \%)$ and $\mathbf{2} \mathbf{g}(76 \%)$ with an 0 -tolyl and a 1-naphthyl group, respectively, were readily converted to the corresponding nine-membered heterocycles. We continued to question the importance of the electronic properties of this aromatic moiety and demonstrated that electron-withdrawing substituents such as a fluorine (4h) or a trifluoromethyl (4i) group at the para position could be installed. Substitutions at the meta position (3-F for $\mathbf{2} \mathbf{j}$ and $\mathbf{3}-\mathrm{CN}$ for $\mathbf{2 k}$ ) were also tolerated as the expected azonanes $\mathbf{4} \mathbf{j}(\mathbf{9 0 \%})$ and $\mathbf{4 k}(\mathbf{9 8 \%})$ were generated in high yields. Halogen atoms are susceptible to alter the course of this reaction as an oxidative insertion of the $\mathrm{Pd}^{0}$ catalyst can occur. We were pleased to observe the efficient formation of azonanes $4 \mathrm{l}(2-\mathrm{Cl}, 66 \%)$ and $4 \mathrm{~m}(5-$ $\mathrm{Br}-2-\mathrm{OMe}, 76 \%)$. Under the same reaction conditions, azadiene $\mathbf{2 n}(50 \%)$ bearing an electron-rich 2-thiophenyl group was converted to the expected nine-membered ring.

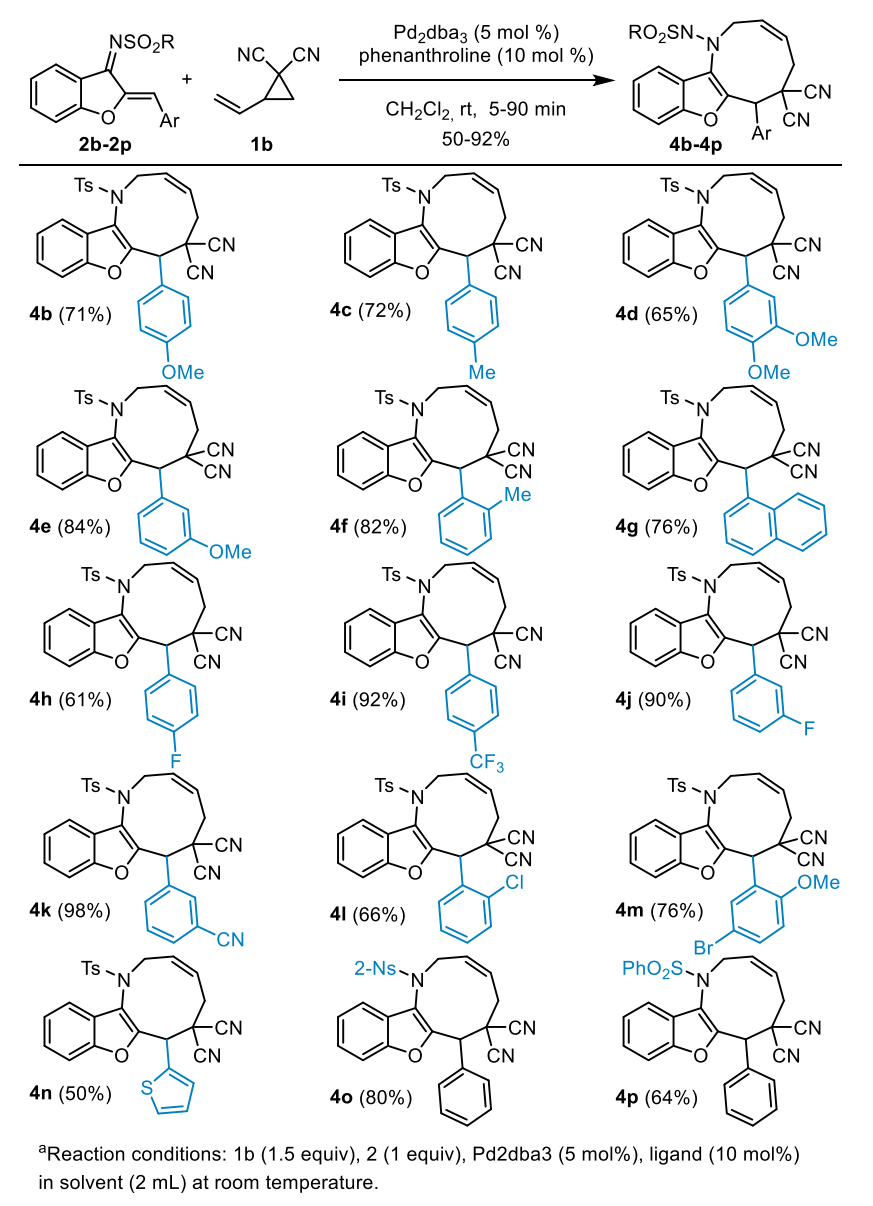

\section{Scheme 3. Formation of benzofuran-fused azonanes ${ }^{a}$}

Finally, the reactivity of benzofuran-derived azadienes with different sulfonamide groups was examined and 2-nitrosulfonamide $40(80 \%)$ as well as benzenesulfonamide $4 p(64 \%)$ were isolated (Scheme 3).

We then focused our attention towards linear 1 -azadienes 6 a-f derived from various chalcones. These substrates present an ambitious challenge as the $(5+4)$ cycloaddition does not come with an aromatization step driving the azadiene to act as a 4-atoms synthon rather than a 2-atom synthon. We first interrogated the behavior of $\mathrm{N}$-Tsazadiene 6 a derived from benzylideneacetophenone and were pleased to observe that the nine-membered heterocycle remained the major product under the previously optimized reaction conditions as a 85:15 mixture of the expected $(5+4)$ cycloadduct $7 a$ along with cyclopentane $8 a$ was obtained $(74 \%)$.The presence of an electronrich aryl $\mathrm{Ar}_{1}$, substituted with a methoxy group at the para position, did not influence the $\mathbf{7 b} \mathbf{b} \mathbf{8 b}(84: 16)$ isomeric ratio but the mixture was isolated in a moderate yield of $47 \%$. Electron-withdrawing groups on $\operatorname{Ar}_{1}$ restored the 
reactivity: azonanes $\mathbf{7 c}$ and $\mathbf{7 d}$ were isolated as the major products with a better selectivity of $90: 10$ and $87: 13$, respectively. The ease of preparation of acyclic 1-azadienes bearing different $\mathrm{Ar}_{2}$ aryl groups allowed us to further review the scope of this monocyclic azonane synthesis. In this case, electrophilic partners with an electron-deficient $p$-nitrophenyl and $p$-trifluoromethylphenyl substituents also reacted promptly to generate $7 \mathbf{e}(7 \mathrm{e} / 8 \mathrm{e}=88: 12)$ and $\mathbf{7 f}(\mathbf{7 f} / \mathbf{8 f}=\mathbf{9 1 : 9})$ with similar selectivities, showing that electronic properties of these 1 -azadienes had little influence on the outcome of the transformation (Scheme 4).

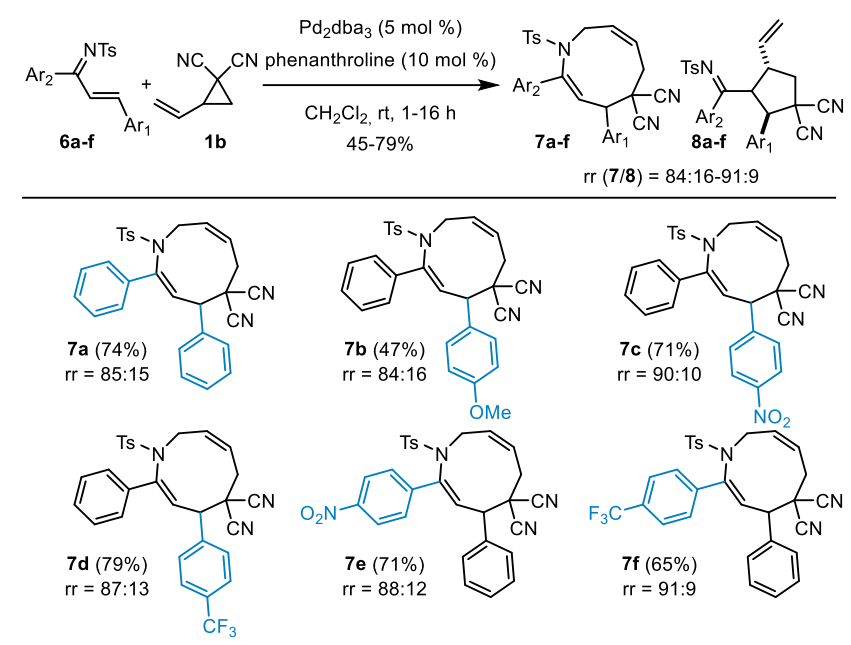

Reaction conditions: $\mathbf{1 b}(0.3 \mathrm{mmol}), \mathbf{2}(0.2 \mathrm{mmol}), \mathrm{Pd}_{2} \mathrm{dba}_{3}(0.01 \mathrm{mmol})$, ligand $(0.02 \mathrm{mmol})$ in solvent $(2 \mathrm{~mL})$ at room temperature.

\section{Scheme 4. (5+4) cycloadditions of linear 1-azadienes. ${ }^{a}$}

A mechanistic rationale was proposed for this $(5+4)$ process relying on Tsuji-Trost chemistry (Scheme 5). After in situ formation of the active 14 electrons complex $\mathrm{Pd}^{0} L_{2}\left(L_{2}=\right.$ phen or dppe), its complexation (not shown) with the alkene moiety of VCP $\mathbf{1 b}$ is then followed by an oxidative addition to generate zwitterionic Pd"-r-allyl complex $\mathbf{A}$. A Michael addition into azadiene $\mathbf{2 a}$ then generates the key $\mathrm{Pd}$ "- $\pi$-allyl complex intermediate $\mathbf{B}$. The formation of the observed nine-membered ring 4 a could result from pathway ( $a$ ) after addition of the sulfonamide anion, acting as a bulky soft nucleophile, to the terminal carbon of the $\pi$-allyl moiety. An alternative pathway $(b)$ involving the nucleophilic addition of the $C_{3}$ carbon onto the substituted carbon of the $\pi$-allyl Pd" complex would then lead to the spiro $(3+2)$ cycloadduct $5 a$, observed as the side product of the transformation when $L_{2}=d p p e$. In this case, the complete conversion of $\mathbf{4 a}$ to $\mathbf{5 a}$ after $4 \mathrm{~h}$ (see Scheme 2) could be explained by the ring-opening of kinetic product $\mathbf{4} \mathbf{a}$ and regeneration of zwitterionic intermediate $\mathbf{B}$ which then cyclizes towards the thermodynamic product 5a (Scheme 5, Eq 1). When $L_{2}=$ phenanthroline, the complete selectivity for the 9-membered ring 4a (Scheme 5 , Eq 2) could be explained by an inhibition of pathway $(b)$ but could also result from a forbidden ring-opening step. We finally established that the lower selectivity for monocyclic azonane $7 \mathrm{a}(1 \mathrm{~h}, \mathbf{7 a} / \mathbf{8 a}=85: 15)$ did not evolve after an extended reaction time (Scheme 5, Eq 3), suggesting that no subsequent ring-opening of 7 a (and by analogy 4 a) occurs with a $N, N$-bidentate ligand. 

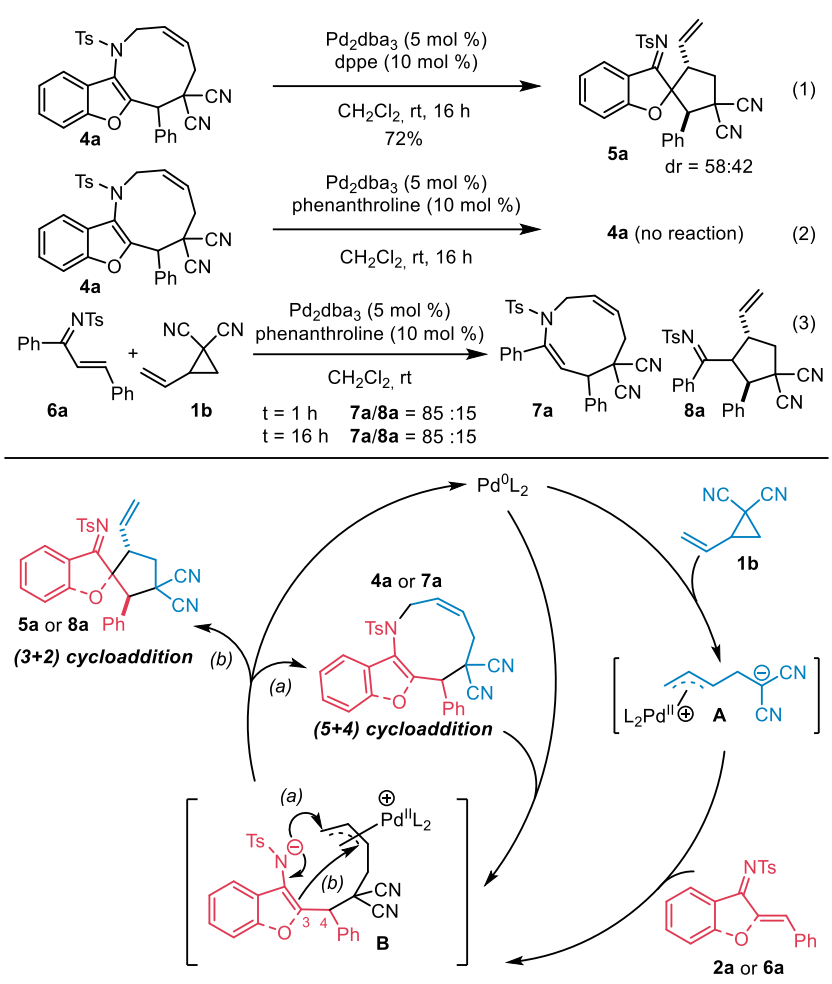

\section{Scheme 5. Control experiments and proposed mechanism.}

In this study, we reported a Pd-catalyzed (5+4) cycloaddition between an activated vinylcyclopropane and 1-azadienes as the electrophilic partner to furnish azonanes, a nine-membered $N$-heterocycle. During this process, the VCP acts as a 5-atom synthon and a $\mathrm{N}, \mathrm{N}$-ligand was necessary to achieve a complete selectivity and avoid the formation of the undesired thermodynamic product originating from a competing $(3+2)$ process. Mechanistic investigations are underway to better understand the selectivity of this transformation with the aim of involving VCPs in other $(5+n)$ cycloadditions.

\section{ASSOCIATED CONTENT}

\section{Supporting Information}

The Supporting Information is available free of charge on the ACS Publications website.

Experimental procedures and NMR spectra for all new compounds (PDF)

\section{Crystallographic data}

CCDC 2058000 (4a) contains the supplementary crystallographic data for this paper and can be obtained free of charge from The Cambridge Crystallographic Data Centre.

\section{AUTHOR INFORMATION}

\section{Corresponding Author}

*E-mail: alexis.archambeau@polytechnique.edu

\section{ORCID}

0000-0002-1311-503X 


\section{Notes}

The authors declare no competing financial interest.

\section{ACKNOWLEDGMENT}

This work was supported by ANR JCJC grant CycloSyn (ANR-18-CE07-0008). A.S. and A.K. thanks Labex CHARMMMAT (ANR-11-LABX-0039) for a M2 grant. A.S. thanks ANR for a PhD fellowship.

\section{REFERENCES}

(1) For books on medium-sized rings synthesis, see: (a) Newkome, G. R.; Eight-Membered and Larger Rings in Progress in Heterocyclic Chemistry; Suschitzky, H., Scriven, E. F. V., Eds.; Elsevier: Amsterdam, The Netherlands, 1991; Volume 3, pp. 319-330; (b) Quirke, J. M. E., Eight-Membered and Larger Rings Systems in Heterocyclic Chemistry; Suschitzky H., Eds.; The Royal Society of Chemistry's Books; Royal Society of Chemistry: London, UK, 1986; Volume 5, pp. 455-481.

(2) For reviews on medium-sized rings, see: (a) Molander, G. A. Acc. Chem. Res. 1998, 31, 603-609; (b) Yet, L. Chem. Rev. 2000, 100, 2963-3007; (c) Maier, M. E. Angew. Chem. Int. Ed. 2000, 39, 2073-2077; (d) Roxburgh, C. J. Tetrahedron 1993, 49, 10749-10784; (e) Donald, J. R.; Unsworth, W. P. Chem. Eur. J. 2017, 23, 8780-8799; (f) Clarke, A. K.; Unsworth, W. P. Chem. Sci. 2020, 11, 2876-2881; (g) Choury, M.; Basilio Lopes, A.; Blond, G.; Gulea, M. Molecules 2020, 25, 3147-3174.

(3) Illuminati, G.; Mandolini, L. Acc. Chem. Res. 1981, 14, 95-102; (b) Galli, C.; Mandolini, L. Eur. J. Org. Chem. 2000, 3117-3125.

(4) De, N.; Yoo, E. J. ACS Catal. 2018, 8, 48-58.

(5) For a recent review, see: Allen, B. D. W.; Lakeland, C. P.; Harrity, J. P. A. Chem. Eur. J. 2017, 23, 13830-13857.

(6) For cycloadditions of cyclic 2-methylidenetrimethylene carbonates, see: (a) Mao, B.; Liu, H.; Yan, Z.; Xu, Y.; Xu, J.; Wang, W.; Wu, Y.; Guo, H. Angew. Chem. Int. Ed. 2020, 59, 11316-11320; (b) Uno, H.; Kawai, K.; Shiro, M.; Shibata, N. ACS Catal. 2020, 10, 14117-14126. For cycloadditions of allyl carbonates bearing a carbinol side-chain, see: (c) Gao, R.-D.; Xu, Q.-L.; Zhang, B.; Gu, Y.; Dain L.-X.; You, S.-L. Chem. Eur. J. 2016, 22, 11601-11604. (d) Yuan, Z.; Pan, R.; Zhang, H.; Liu, L.; Lin, A.; Yao H. Adv. Synth. Catal. 2017, 359, 4244-4249.

(7) For a VCP involved as a 1,5-oxa-dipole, see: Li, M.-M.; Xiong, Q.; Qu, B.-L.; Xiao, Y.-Q.; Lan, Y.; Lu, L.-Q.; Xiao, W.-J. Angew. Chem. Int. Ed. 2020, 59, 17429-17434.

(8) For selected examples, see: (a) Rong, Z.-Q.; Yang, L.-C.; Liu, S.; Yu, Z.; Wang, Y.-N.; Tan, Z. Y.; Huang, R.-Z.; Lan, Y.; Zhao, Y. J. Am. Chem. Soc. 2017, 139, 15304-15307; (b) Yang, L.-C.; Rong, Z.-Q.; Wang, Y.-N.; Tan, Z. Y.; Wang, M.; Zhao, Y. Angew. Chem. Int. Ed. 2017, 56, 2927-2931; (c) Yang, Y.; Yang, W. Chem. Commun. 2018, 54, 12182-12185; (d) Das, P.; Gondo, S.; Nagender, P.; Uno, H.; Tokunaga, E.; Shibata, N. Chem. Sci. 2018, 9, 3276-3281; (e) Wei, Y.; Liu, S.; Li, M.-M.; Li, Y.; Lan, Y.; Lu, L.-Q.; Xiao, W.-J. J. Am. Chem. Soc. 2019, 141, 133-137; (f) Zhang, X.; Li, X.; Li, J.L.; Wang, Q.-W.; Zou, W.-L.; Liu, Y.-Q.; Jia, Z.-Q.; Peng, F.; Han, B. Chem. Sci. 2020, 11, 2888-2894; (g) Uno, H.; Punna, N.; Tokunaga, E.; Shiro, M.; Shibata, N. Angew. Chem. Int. Ed. 2020, 59, 8187-8194.

(9) For examples involving vinyloxetanes as oxa-1,6-dipoles precursors, see: (a) Wang, Y.-N.; Yang, L.-C.; Rong, Z.Q.; Liu, T.-L.; Liu, R.; Zhao, Y. Angew. Chem. Int. Ed. 2018, 57, 1596-1600; (b) Uno, H.; Imai, T.; Harada, K.; Shibata, N. ACS Catal. 2020, 10, 1454-1459.

(10) For a (4+2) cycloaddition using a cyclic carbamate, see: Allen, B. D. W.; Connolly, M. J.; Harrity, J. P. A. Chem. Eur. J. 2016, 22, 13000-13003.

(11) For selected examples, see: (a) Wang, C.; Tunge, J. A. J. Am. Chem. Soc. 2008, 130, 8118-8119; (b) Leth, L. A.; Glaus, F.; Meazza, M.; Fu, L.; Thørgensen, M. K.; Bitsch, E. A.; Jørgensen, K. A. Angew. Chem. Int. Ed. 2016, 55, 15272-15276; (c) Guo, C.; Fleige, M.; Janssen-Müller, D.; Daniliuc, C. G.; Glorius, F. J. Am. Chem. Soc. 2016, 138, 7840-7843; (d) Li, M.-M.; Wei, Y.; Liu, J.; Chen, H.-W.; Lu, L.-Q.; Xiao, W.-J. J. Am. Chem. Soc. 2017, 139, 1470714713; (e) Lu, Y.-N.; Lan, J.-P.; Mao, Y.-J.; Wang, Y.-X.; Mei, G.-J.; Shi, F. Chem. Commun. 2018, 54, 13527-13530; (f) Wang, Y.-N.; Xiong, Q.; Lu, L.-Q.; Zhang, Q.-L.; Wang, Y.; Lan, Y.; Xiao, W.-J. Angew. Chem. Int. Ed. 2019, 58, 1101311017.

(12) For selected examples, see: (a) Shintani, R.; Murakami, M.; Hayashi, T. J. Am. Chem. Soc. 2007, 129, 1235612357; (b) Shintani, R.; Park. S.; Hayashi, T. J. Am. Chem. Soc. 2007, 129, 14866-14867; (c) Shintani, R.; Park, S.; Shirozu, F.; Murakami, M.; Hayashi, T. J. Am. Chem. Soc. 2008, 130, 16174-16175. 
(13) Trost, B. M.; Jiao, Z.; Liu, Y.; Min, C.; Jung, C.-I. J. J. Am. Chem. Soc. 2020, 142, 18628-18636.

(14) Trost, B. M.; Jiao, Z. J. Am. Chem. Soc. 2020, 142, 21645-21650.

(15) For selected examples of VCP as 5-carbon synthon in Rh catalysis, see: (a) Wender, P. A.; Takahash, H.; Witulski, B. J. Am. Chem. Soc. 1995, 117, 4720-4721; (b) Wender, P. A.; Barzilay, C. M.; Dyckman, A. J. J. Am. Chem. Soc. 2001, 123, 179-180; (c) Wender, P. A.; Haustedt, L. O.; Lim, J.; Love, J. A.; Williams, T. J.; Yoon, J.-Y. J. Am. Chem. Soc. 2006, 128, 6302-6303; (d) Shintani, R.; Nakatsu, H.; Takatsu, K.; Hayashi, T. Chem. Eur. J. 2009, 15, 8692-8694; (e) Liu, C.-H.; Yu, Z.-X. Angew. Chem. Int. Ed. 2017, 56, 8667-8671. For selected examples of VCP as 5-carbon synthon in Ru catalysis, see: (f) Trost, B. M.; Toste, F. D.; Shen, H. C. J. Am. Chem. Soc. 2000, 122, 2379-2380; (g) Trost, B. M.; Shen H., Angew. Chem. Int. Ed. 2001, 40, 2313-2316.

(16) For selected examples, see: (a) Shimizu, I.; Ohashi, Y.; Tsuji, J. Tetrahedron Lett. 1985, 26, 3825-3828; (b) Trost, B. M.; Morris, P. J. Angew. Chem. Int. Ed. 2011, 50, 6167-6170; (c) Mei, L.-Y.; Wei, Y.; Xu, Q.; Shi, M. Organometallics 2012, 31, 7591-7599; (d) Liu, Z.-S.; Li, W.-K.; Kang, T.-R.; He, L.; Liu, Q. Z.; Org. Lett. 2015, 17, 150-153; (e) Xie, M.-S.; Wang, Y.; Li, J.-P.; Du, C.; Zhang, Y.-Y.; Hao, E.-J.; Zhang, Y.-M.; Qu, G.-R.; Guo, H. M. Chem. Commun. 2015, 51, 12451-12454; (f) Laugeois, M.; Ponra, S.; Ratovelomanana-Vidal, V.; Michelet V.; Vitale, M. R. Chem. Commun. 2016, 52, 5332-5335; (g) Halskov, K. S.; Næsborg, L.; Tur F.; Jørgensen, K. A. Org. Lett. 2016, 18, 2220-2223.

(17) During the preparation of this manuscript, the groups of Trost and Li published a study on an enantioselective version of this (3+2) cycloaddition with VCP 1a and 1b: (a) Trost. B. M.; Zuo, Z. Angew. Chem. Int. Ed. 2021, DOI: 10.1002/anie.202016439; (b) Liu, K.; Yang, J.; Li, X. Org. Lett. 2021, DOI: 10.1021/acs.orglett.0c04062.

(18) XRD analysis of 4a: CCDC 2058000.

(19) VCPs bearing two sulfones groups or derived from Meldrum's acid showed no reactivity with 2a under the same conditions. 